\title{
Special Access Denied: A Case Study of Health Canada's Special Access Program
}

\section{Accès spécial refusé : une étude de cas sur le Programme d'accès spécial de Santé Canada}

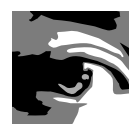

\author{
by TIMOTHY K.S. CHRISTIE, PHD, MHSC \\ British Columbia Centre for Excellence in HIV/AIDS \\ University of British Columbia \\ Atlantic Health Sciences Corporation \\ Providence Health Care, Vancouver, BC \\ MARIANNE HARRIS, MD, CCFP \\ British Columbia Centre for Excellence in HIV/AIDS \\ Providence Health Care, Vancouver, BC \\ JULIO S.G. MONTANER, MD, FRCPC \\ British Columbia Centre for Excellence in HIV/AIDS \\ University of British Columbia \\ Providence Health Care, Vancouver, BC
}

\begin{abstract}
This paper examines the ethical probity of Health Canada's Special Access Program (SAP). The SAP is designed for patients with life-threatening conditions who require "emergency" access to drugs that are not authorized for use in Canada when conventional therapies have failed. We argue that the SAP inappropriately uses the tenets of
\end{abstract}


evidence-based decision-making in situations where evidence-based decision-making is unfeasible. The SAP should abandon its pretence of evidence-based decision-making and adopt a transparent process in which the values guiding decisions are explicit and corrigible. We recommend the ethical principles of autonomy, non-maleficence, beneficence and justice.

\section{Résumé}

Cet article examine la probité déontologique du Programme d'accès spécial (PAS) de Santé Canada. Le PAS est conçu pour les patients atteints de maladies graves contre lesquelles les traitements traditionnels ont échoué et qui ont besoin d'un accès « urgent » à des médicaments dont l'utilisation nest pas autorisée au Canada. Nous soutenons que le PAS utilise un processus décisionnel fondé sur des preuves dans des situations où un tel processus n'est pas faisable. Le PAS devrait cesser cette pratique et adopter un processus transparent où les valeurs guidant les décisions sont explicites et corrigibles. Nous recommandons notamment un processus fondé sur les principes déontologiques d'autonomie, de non-malfaisance, de bienfaisance et de justice.

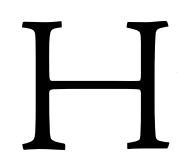

Ealth Canada's Special Access Program (SAP) is a means whereby healthcare practitioners can request limited access to drugs that are not authorized for sale in Canada. Usually, the drugs are early in development or have not completed the formal study process required for licensing. The SAP is designed for patients with life-threatening conditions who require "emergency" and/or "compassionate" access to drugs when conventional therapies have "failed, are unsuitable, or are unavailable" (Health Canada 2005a). It operates under Part C, Division 8 of the Food and Drug Regulations, which permit the Director to authorize the release of a drug for the emergency treatment of a patient receiving care from a medical practitioner (Department of Justice 2004). The practitioner is required to provide information about the medical emergency and data about "use, safety and efficacy," and to satisfy other administrative requirements.

This paper critically assesses the criteria used by the SAP in approving or denying an application. We present a case series that illustrates an emergency health situation where all available therapies have failed. We then highlight the results of a Global National investigational report that exposes the actual operations of the SAP. We argue that the SAP is flawed because it uses the rhetoric of evidence-based decisionmaking inappropriately. Finally, the SAP would be improved if it adopted explicit ethical principles to guide its decision-making processes. 


\section{Case Studies}

Our clinic had six HIV-positive patients for whom all conventional antiretroviral therapies had failed. Each patient had long-standing HIV infection with advanced immunodeficiency. All had been diagnosed with AIDS and had low CD4+ cell counts with high plasma viral loads. They had received multiple combination treatment regimens, including multi-drug salvage therapy, which failed to control their HIV disease. Genotypic testing confirmed that their HIV had become highly resistant to conventional antiretroviral agents. Their treatment options were further limited by previous intolerance and toxicity. They had advanced HIV disease with multi-drug resistant virus and no viable treatment options using currently approved antiretroviral agents.

TMC125 and TMC114 are investigational agents that have significant potential for the treatment of drug-resistant HIV (Katlama, Berger et al. 2005; Katlama, Carvalho et al. 2005; Montaner et al. 2005; Nadler et al. 2005). Limited data are available regarding the use of these agents; however, each drug has been evaluated in dose range-finding stud-

\section{Used in combination, these drugs may have the potential to stabilize their HIV disease and keep these patients alive until other options become available.} ies (including in Canada) with encouraging results. Given the advanced stage of disease in these patients and what is known about the detrimental effects of monotherapy, sequential use of these drugs would further compromise their effectiveness. Used in combination, these drugs may have the potential to stabilize their HIV disease and keep these patients alive until other options become available. The available data show no adverse events from using these two drugs in combination. In fact, they have in vitro synergistic rather than antagonistic effects.

TMC125 and TMC114 are not approved for marketing in Canada; therefore, we applied to the SAP to use them in combination. Our application was denied because there was a "lack of sufficient data to support the use of these two products in combination" (Health Canada 2005b). We appealed this decision, but the appeal was denied. The reasoning again focused on lack of supporting evidence. Of note, our patients' applications were initially filed in April 2005. Since then, one of the applicants has died from complications related to HIV. Ironically, a recent story by Global National revealed that $67 \%$ of SAP requests annually are for breast implant devices and, as of June 2006, the SAP approved 26,000 requests for silicone implants (Global National 
2006). The cosmetic surgeons interviewed explained that "small breasts" and "slight rippling of the skin through saline implants" are the life-threatening conditions for which implants are sought (Global National 2006).

\section{Analysis}

This critique is not restricted to accessing TMC125 and TMC114; rather, it is a criticism of the SAP's decision-making process. The SAP has "discretionary authority" to authorize or deny requests on a case-by-case basis. Of central importance to this discretionary authority is the quantity of data available to support the "use, safety and efficacy" of a proposed regimen. However, it is not clear how much data is necessary to satisfy the SAP of a drug's use, safety and efficacy. The standards against which the data are interpreted, the types of data that are considered satisfactory and the study designs that are acceptable remain unknown. The SAP is flawed because it professes to make evidence-based decisions in situations where evidence-based decision-making is impossible. Data pertaining to experimental drugs that are in early stages of development or that have not been formally tested cannot meet the standards that constitute evidence. The SAP concedes this point in one of its publications:

SAP authorization does not constitute an opinion or statement that a drug is safe, efficacious or of high quality. The SAP does not conduct a comprehensive evaluation to ensure the validity of drug information or attestations of the manufacturer respecting safety, efficacy and quality. (Health Canada 2003)

Our experience leads to three possible conclusions: (1) the SAP does make decisions about safety and efficacy; (2) the SAP uses its discretionary authority arbitrarily, based on subjective assessments of data; or (3) the SAP renders value-laden decisions camouflaged in the language of evidence-based decision-making. A combination of these is operational in our case. Stated reasons for denying our application confirm that (1) the SAP does make decisions about safety and efficacy and (2) the SAP exercises discretionary authority based on subjective assessments of the data. Also, (3) the SAP renders value-laden decisions camouflaged in the language of evidence-based decision-making; while this is implicit in its reasoning, further elaboration is required to make this explicit.

In the absence of adequate evidence, a decision still has to be made about whether to approve an application, and it is at this point that value-laden decisions are made. Where decisions are not based on evidence, they are based on values - economic, moral, legal, etc. - regardless of whether those values are explicit. One way to improve this program is to be frank about the limitations of data in this context and acknowledge explicitly that values-based reasoning is being applied. Our concern with the SAP 
is that the values employed are not explicit or corrigible. Therefore, we suggest that the program would be improved if it adopted explicit ethical principles that are consistent with the mandate of providing emergency or compassionate access to drugs. This would allow the SAP to abandon the pretence of evidence-based decision-making.

\section{An Alternative Proposal}

Explicit values-based reasoning could employ the ethical principles of autonomy, beneficence, non-maleficence and justice (Beauchamp and Childress 2001: 114). These principles have been formally endorsed by important government bodies in the United States and Canada: the National Commission for the Protection of Human Subjects of Biomedical and Behavioral Research (USA, 1979); the President's Commission for the Study

... it is not enough for a person to enter an agreement fully informed and without coercion, but the person's decision must be consistent with his or her deepest values. of Ethical Problems in

Medicine and Biomedical and Behavioral Research (USA, 1978); the Medical Research Council of Canada (1987), now the Canadian Institutes for Health Research; and the legal systems of most democracies. We emphasize the deliberative aspects of the principled approach because the SAP, in order to run properly, requires a certain degree of flexibility. The Belmont Report (National Commission for the Protection of Human Subjects 1978) explained that these principles cannot always be applied so as to resolve beyond dispute particular ethical problems; rather, they can provide an analytical framework that can help guide the resolution of difficult ethical problems.

\section{Autonomy}

Respect for the principle of autonomy is commonly articulated through the doctrine of informed consent. Informed consent requires that every patient be informed to the extent that a reasonable person in that patient's position would require (Reibl v. Hughes 1980). Regarding SAP applications, it seems sensible to insist that the patient be fully informed of everything the physician knows about the experimental drugs rather than just the information that a reasonable person would want. The idea would be to empower the patient to decide whether to accept the risks of using these drugs.

Embedded in the doctrine of informed consent is the idea that it must be vol- 
untary. When patients require emergency or compassionate access to drugs because of a life-threatening condition, it is fair to assume that the patient will be somewhat vulnerable. Sue Sherwin, in her work on "relational autonomy," explains that it is not enough for a person to enter an agreement fully informed and without coercion, but the person's decision must be consistent with his or her deepest values. Without completely endorsing the notion of "relational autonomy," it would make sense for the SAP to insist that physicians be able to demonstrate that their request is consistent with the patient's enduring values. The magnitude of vulnerability, however, should not be overstated. For example, many HIV-positive patients have lived with the disease for a long time and have clear opinions, consistent with their deepest values, about what they want and do not want if their drug regimens fail. Some patients would not be willing to take experimental medications because they find it difficult to take approved medications with known risks, let alone experimental medications with unknown risks.

\section{Non-maleficence}

Another precaution against vulnerability is the principle of non-maleficence, which is referred to as "primum non nocere," meaning "above all, do no harm." Non-maleficence requires that individuals refrain from doing harm to others. The application of nonmaleficence requires the physician to convince the SAP that the patient will not be unnecessarily harmed. In our application, for example, we emphasized that we intended to monitor these patients very closely in terms of the safety and efficacy of the regimen, and would withdraw treatment if it became toxic or ineffective. Treatment would be administered under the supervision of an experienced HIV physician.

\section{Beneficence}

The principle of beneficence requires that individuals attempt to contribute to the welfare of others, a positive duty to help. With regard to the SAP, the principle of beneficence could require the physician to provide the program with whatever data are available on the requested drugs, a physiological rationale for why these drugs should help and a rigorous justification of the physician's professional recommendation. This requirement would preclude the possibility that the SAP is being used for pilot studies on unsuspecting patients.

\section{Justice}

At a minimum, the principle of justice requires that like cases be treated alike and that decision-making not be arbitrary. This principle would ensure that all decisions by the SAP are consistent with the values of emergency or compassionate access. It would 
also guarantee that the "discretionary authority" of the Director does not turn into arbitrary or unprincipled decision-making.

\section{Conclusion}

In conclusion, a critic of our position could argue that limiting the use of evidence in the way we propose could result in patients' suffering serious harm that could have been prevented had proper attention been paid to the available evidence. Nothing in our position should be interpreted as an argument for not considering the evidence. Our position is that it is inappropriate to deny applications solely because there is a lack of evidence about "use, safety and efficacy." Many of the drugs requested through the SAP may not have supporting evidence. Unfortunately, for some patients, "conventional therapies have failed, are unsuitable or are unavailable," and it is for these people that we suggest the focus should shift from a hobbled evidence-based approach to ethical principles. At a minimum, decisions must be transparent, corrigible and ethically justifiable.

Correspondence may be directed to: Dr. Julio Montaner, Director, BC Centre for Excellence in HIV/AIDS, St. Paul's Hospital, 1081 Burrard St., Vancouver, BC V6Z 1Y6; tel.: 604-806-8036; fax:604-806-8527; email: jmontaner@cfenet.ubc.ca.

\section{ACKNOWLEDGMENTS}

The authors would like to acknowledge members of the Committee on Drug Evaluation and Therapy of the BC Centre for Excellence in HIV/AIDS and Anne Drummond, Medical Writer, BC Centre for Excellence in HIV/AIDS, for their comments on the penultimate version of this paper. Also, we would like to acknowledge the helpful comments provided by the peer reviewers and editors of Healthcare Policy. Their insights have greatly improved this manuscript.

\section{REFERENCES}

Beauchamp, T.L. and J.F. Childress. 2001. Principles of Biomedical Ethics (5th ed.). New York: Oxford University Press.

Department of Justice Canada. 2004 (August 31). Food and Drug Regulations. Part C, Division 8: New Drugs. Retrieved September 25, 2006. <http://laws.justice.gc.ca/en/F-27/C.R.C.c.870/125556.html>.

Global National. 2006 (February 16). "Loophole Allows Banned Silicone Implants." Retrieved September 25, 2006. <http://www.canada.com/globaltv/national/story.html?id=f4ba541d-bd2e4302-81dd-623b8cffb33f $>$.

Health Canada. 2003 (August 24)."Special Access Programme (SAP) - Instructions for Making a Special Access Request." Retrieved September 25, 2006. <http://www.hc-sc.gc.ca/dhp-mps/ acces/drugs-drogues/sapg2_pasg2_e.html>. 
Health Canada. 2005a (August). "Drugs and Health Products." Retrieved September 25, 2006. <http://www.hc-sc.gc.ca/dhp-mps/acces/drugs-drogues/index_e.html>.

Health Canada. 2005b (September 16). Letter from the Scientific Regulatory Officer of the Special Access Program to Dr. Harris at the BC Centre for Excellence in HIV/AIDS.

Katlama, C., D. Berger, N. Bellos et al. 2005."Efficacy of TMC114/r in 3-Class Experienced Patients with Limited Treatment Options: 24-Week Planned Interim Analysis of 2 96-week Multinational Dose-Finding Trials." Twelfth Conference on Retroviruses and Opportunistic Infections, Boston, USA, February 22-23.

Katlama, C., M.T. Carvalho, D. Cooper et al. 2005.“TMC114/r Outperforms InvestigatorSelected PI(s) in 3-Class-Experienced Patients; Week 24 Primary Analysis of POWER 1 (TMC114-C213)." Third IAS Conference on HIV Pathogenesis and Treatment, Rio de Janeiro, Brazil, July 24-27.

Montaner, J., P. Domingo, P. Junod et al. 2005. "Safety and Tolerability of TMC125 in 3-ClassExperienced HIV-Infected Patients: 24-Week Primary Analysis of Trial TMC125-C203." Tenth European AIDS Conference/EACS, Dublin, Ireland, November 17-20.

Nadler, J.P., H.A. Grossman, C. Hicks et al. 2005. "Efficacy and Tolerability of TMC125 in HIV Patients with NNRTI and PI Resistance at 24 Weeks: TMC125-C223." Tenth European AIDS Conference/EACS, Dublin, Ireland, November 17-20.

National Commission for the Protection of Human Subjects of Biomedical and Behavioural Research. 1979. The Belmont Report: Ethical Principles and Guidelines for the Protection of Human Subjects of Research. Department of Health, Education and Welfare. Retrieved November 8, 2006. <http://ohsr.od.nih.gov/guidelines/belmont.html>.

Reibl v. Hughes [1980] 2 SCR 880, 14 CCLT 1, 14 DLR(3d) 1, 33 NR 361

United States President's Commission for the Study of Ethical Problems in Medicine and Biomedical and Behavioral Research. Making Health Care Decisions: The Ethical and Legal Implications of Informed Consent in the Patient-Practitioner Relationship. 1982; Title 42 Sect. $300 \mathrm{v}$ as added 1978. 